\title{
Especificidades da tradução de histórias em quadrinhos: abordagem inicial
}

\section{Comics translation particularities: Initial approach}

\section{Érico Gonçalves de Assis*}

Resumo: A tradução de histórias em quadrinhos (HQs) constitui um campo dos Estudos da Tradução ainda pouco explorado, de forma que não há um fundamento teórico específico relacionado à prática. A produção mundial recente de quadrinhos particularmente das chamadas graphics novels ou novelas gráficas -, contudo, promove um status à mídia comparável ao da literatura, o que gera sua maior aceitabilidade como produto cultural relevante e objeto de estudo acadêmico. Dado deste contexto, o artigo almeja construir linhas-guia para entendimento específico da tradução de HQs no que esta difere da tradução de outras mídias. Para isto, propõe cinco especificidades desta modalidade de tradução: (1) ingerência do tradutor reduzida às unidades de material linguístico; (2) indissolubilidade da mancha gráfica; (3) indissolubilidade das quebras verbais; (4) documento de tradução = roteiro para letreirista; (5) o letreirista como cotradutor.

Palavras-chave: Tradução; histórias em quadrinhos; letreiramento.

Abstract: Comic book translation still is a relatively unexplored area in Translation Studies. Therefore, there is few theoretical footing specifically related to it. Recent worldwide comic book production - especially related to so-called "graphic novels" -, however, posits a status for comics similar to the one attributed to literature, which means comic books are being more accepted as significant cultural objects, as well as research objects. From this context, this projects aims to propose guidelines for

* Tradutor inglês-português e doutorando do Programa de Pós-Graduação em Estudos da Tradução da UFSC. Bolsista Capes. http://lattes.cnpq.br/1240017887383563. ericoassis@gmail.com. Texto submetido em novembro de 2013.

TradTerm, São Paulo, v. 27, Setembro/2016, pp. 15-37

www.usp.br/tradterm

http://www.revistas.usp.br/tradterm/index 
ASSIS, É. G. DE - Especificidades da tradução de histórias em quadrinhos: abordagem inicial

the specific understanding of comic book translation, as compared to translations practices in other media. Therefore, it presents five specifics proper to this kind of translation: (1) the linguistic content units-only translator intervention; (2) layoutbinding; (3) verbal break indissolubility; (4) translation document = letterer script; (5) the letterer as cotranslator.

Keywords: Translation; comic books; lettering.

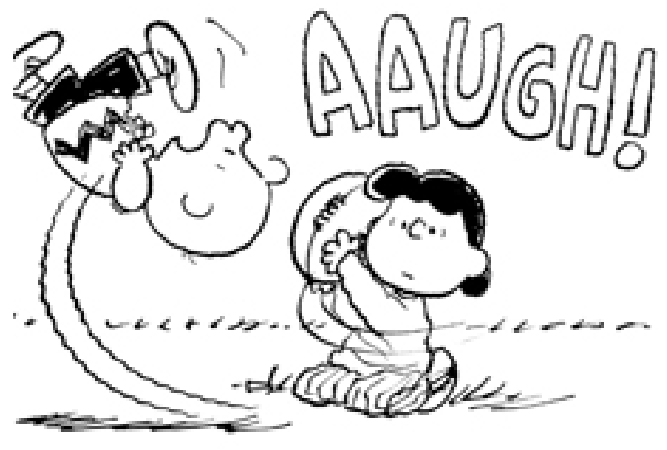

Fig. 1:

http: / / retconredux.blogspot.com.br/2008/01/ competition-was-tough.html

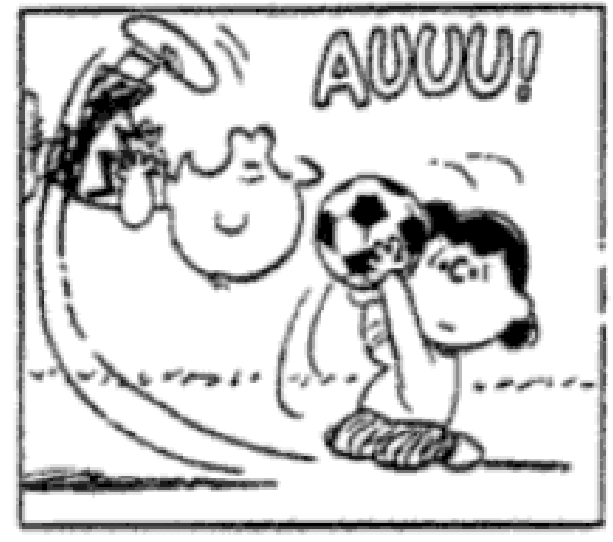

Fig. 2: Kaindl, 2004, pp. 185

No universo da tira Peanuts (1950-2000), de Charles Schulz, a cena acima era recorrente: a menina Lucy e o protagonista Charlie Brown brincavam de futebol americano; ela segurava a bola para o menino vir correndo e chutar; no último momento, Lucy tirava a bola do chão e Charlie Brown dava um chute no ar que o fazia sair voando.

Segundo Kaindl (2004: 184-185), as traduções da tira publicadas na revista alemã Stern faziam uma adaptação no desenho: a bola de futebol americano (Fig. 1) virava uma bola do futebol que as crianças brincam na Alemanha e no resto do mundo (Fig. 2). O propósito seria aproximar o conteúdo da tira à cultura das crianças alemãs. Apesar do intento 
ASSIS, É. G. DE - Especificidades da tradução de histórias em quadrinhos: abordagem inicial

domesticador, explica o autor, a alteração no desenho provocava uma mudança de significado da cena e/ou nas intenções de Lucy: enquanto é necessário e comum outra pessoa segurar a bola oval do futebol americano em posição horizontal para o outro jogador chutar, não há necessidade de alguém segurar a bola redonda do outro estilo de futebol.

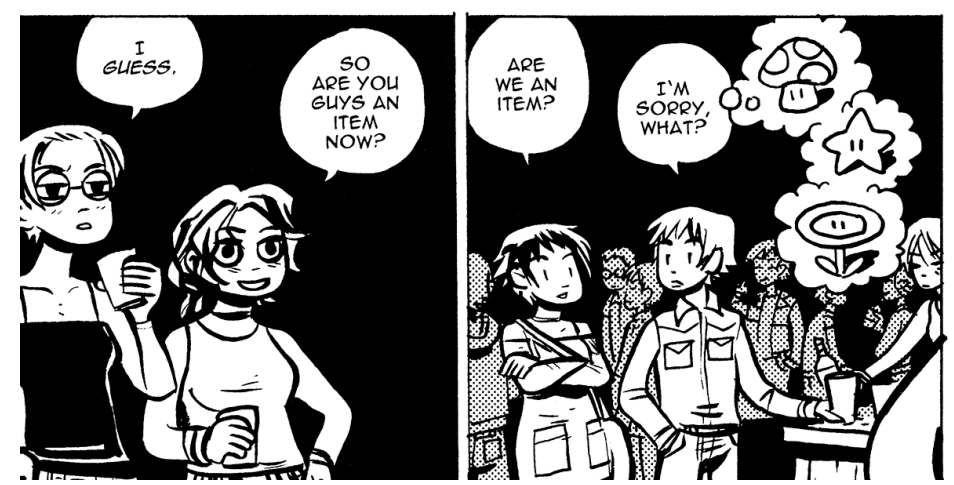

Fig. 3: O’Malley, 2005, pp. 173

Diferente do exemplo anterior, a grande maioria das traduções de quadrinhos contemporâneas evita ou é coagida ${ }^{1}$ a não realizar alterações nos desenhos do texto de partida. A concatenação entre desenhos e material linguístico é, contudo, propriamente o texto quadrinístico. O tradutor, porém, comumente só terá ingerência sobre o material linguístico.

No exemplo acima (Fig. 3), da HQ Scott Pilgrim contra o Mundo de Bryan Lee O’Malley, uma ambiguidade no material linguístico - a palavra item, que no inglês tem o significado de casal e também de objetos coletados por um jogador num videogame como Super Mario - gera uma piada representada nos desenhos. 0 trecho tem relevância para o desenrolar da trama, pois deve abordar a situação do namoro entre o casal do quadro à direita e ao mesmo tempo mostrar a incompreensão ou falta de tato do personagem masculino (protagonista da HQ).

\footnotetext{
1 Por exigências contratuais, por pressão de leitores e críticos com acesso à publicação original, por prejuízo ao ritmo de produção (arquitetado acima de tudo para alterações apenas no material linguístico), entre outros motivos.
} 
ASSIS, É. G. DE - Especificidades da tradução de histórias em quadrinhos: abordagem inicial

O duplo sentido da palavra item é particular à língua inglesa. 0 tradutor, aqui, é requisitado a manter as prováveis intenções do texto quadrinístico original - a referência ao namoro e a piada resultante da ambiguidade -, e ainda está ancorado aos desenhos presente nos balões de pensamento do personagem masculino, que demandam a referência aos items de jogos de videogame.

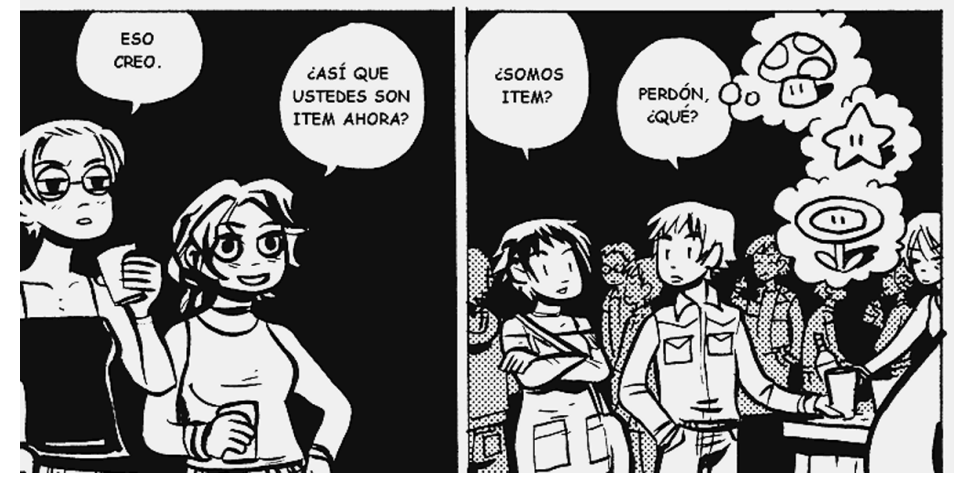

Fig. 4: Disponível em:

www.thepiratebay.sx/torrent/7175011/Scott_Pilgrim_Espa_ntilde_ol.rar

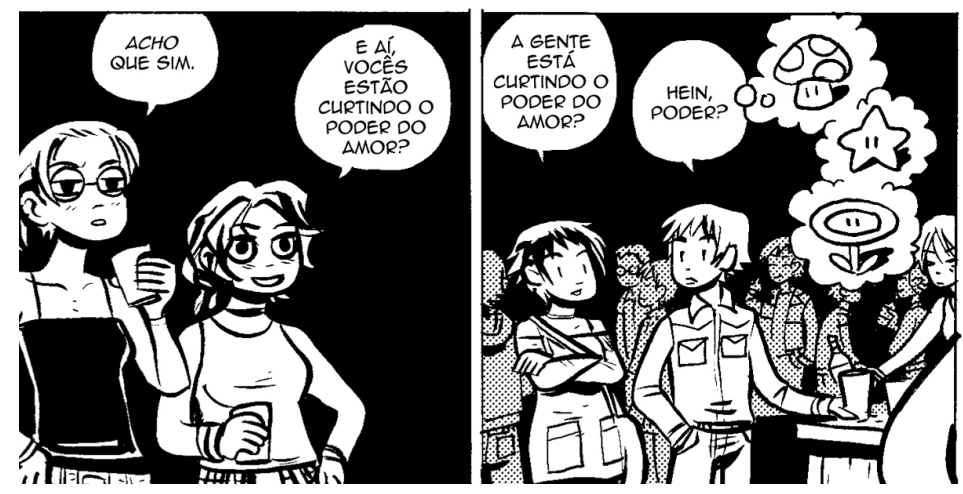

Fig. 5: O’Malley, 2010, pp. 354.

Enquanto a tradução para o espanhol (Fig. 4) ignora o duplo sentido original da palavra "item", a tradução para o português (Fig. 5) busca criar uma nova ambiguidade a partir da palavra "poder" (entendendo que os itens de jogos de videogame concedem poderes ao jogador). Se uma tradução em prosa, por exemplo, poderia estabelecer outras ambiguidades em torno do 
ASSIS, É. G. DE - Especificidades da tradução de histórias em quadrinhos: abordagem inicial

tema “namoro", aqui o tradutor não pode safar-se da âncora pictórica vista nos balões de pensamento.

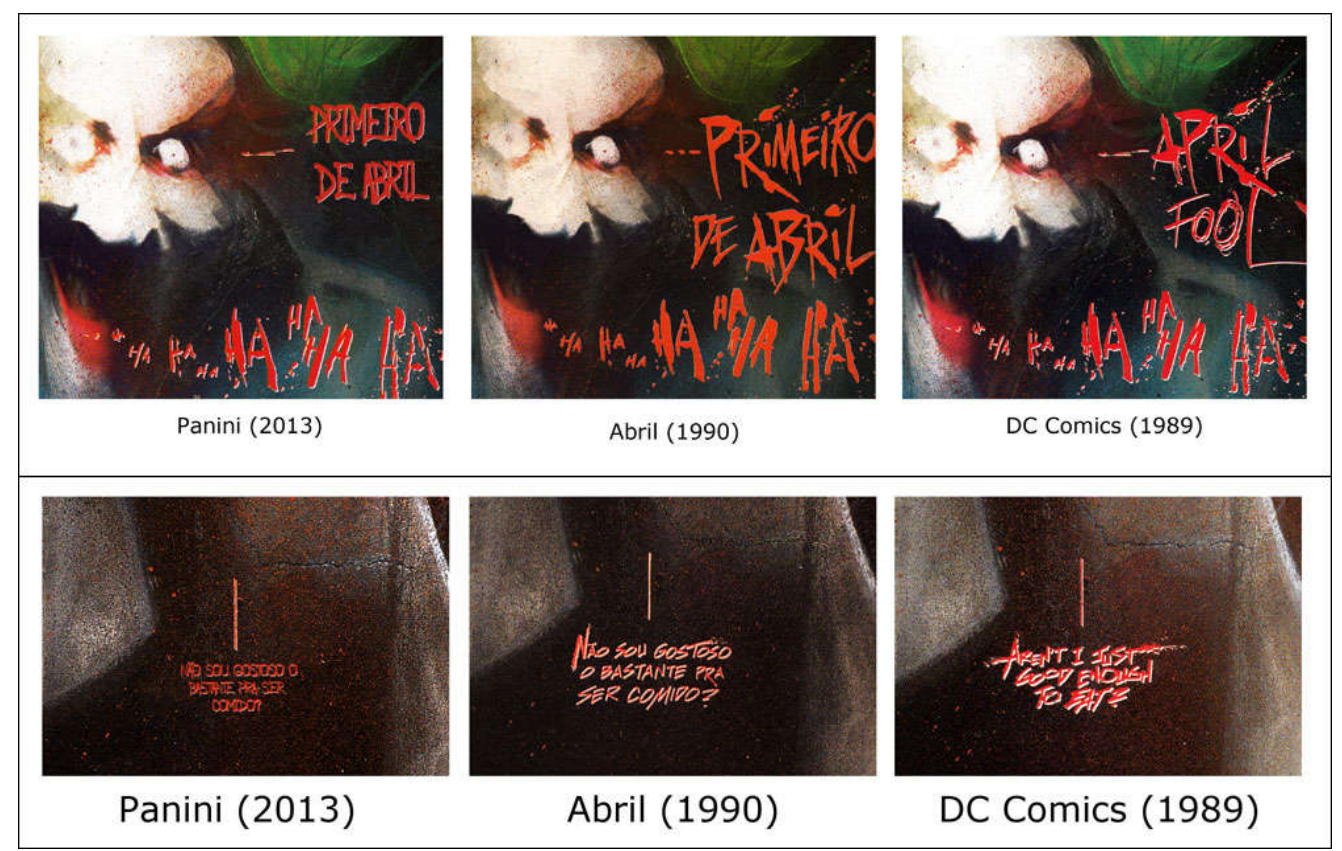

Fig. 6 e Fig. 7: Paz, 2013, online.

A graphic novel Asilo Arkham, estrelando o personagem Batman, foi lançada originalmente em 1989 com uma proposta gráfica diferente dos quadrinhos tradicionais de super-herói: o ilustrador Dave McKean utilizou arte pintada, fotografia e outras técnicas artísticas na produção das páginas, além de ter dado atenção específica a como a tipografia poderia ser utilizada na caracterização de cada personagem ou de determinadas frases destes personagens.

Na tradução brasileira da obra publicada em 2013 pela editora Panini, parte desta caracterização tipográfica foi desconsiderada. Como aponta a resenha de Paz (2013, online), “todos os caracteres ficaram com o mesmo tamanho, padronizados mecanicamente. Toda a expressividade da caligrafia manual foi perdida, perdeu-se toda a organicidade de textos e falas, deixando-os mecânicos, padronizados e sem expressão. Chegam a destoar da arte de McKean”. Nas imagens acima (Fig. 6 e 7), a resenha ainda expõe em 
ASSIS, É. G. DE - Especificidades da tradução de histórias em quadrinhos: abordagem inicial

comparação outra tradução publicada no Brasil, pela editora Abril em 1990, onde o letreiramento à mão buscou reproduzir o texto de partida.

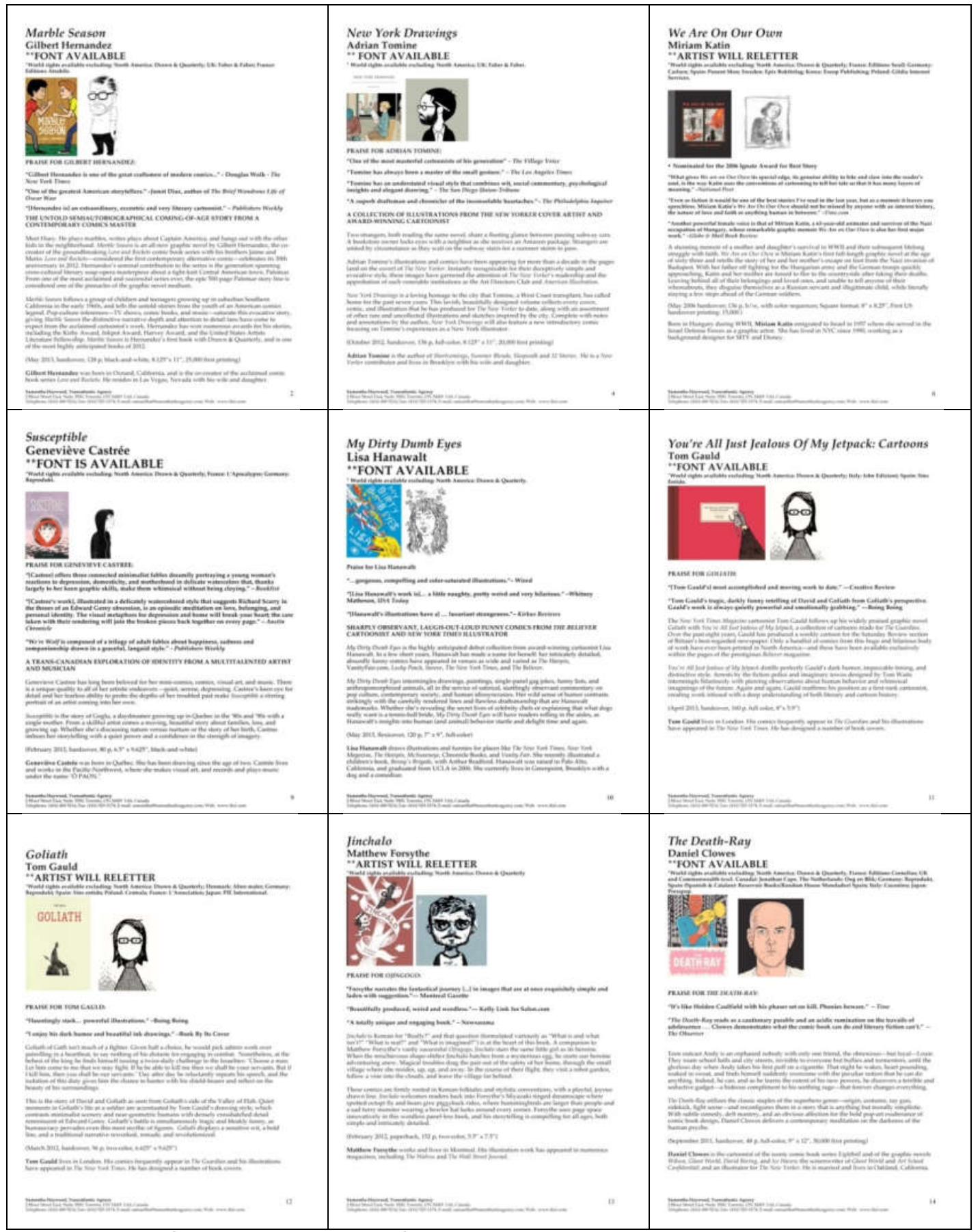

Fig. 8: Páginas avulsas de catálogo da editora canadense Drawn \& Quarterly (TRANSATLANTIC AgENCY 2012).

TradTerm, São Paulo, v. 27, Setembro/2016, pp. 15-37 www.usp.br/tradterm http://www.revistas.usp.br/tradterm/index 
ASSIS, É. G. DE - Especificidades da tradução de histórias em quadrinhos: abordagem inicial

A comercialização de direitos de republicação de quadrinhos atingiu novo patamar na primeira década do século XXI com o aquecimento do mercado de graphic novels ou novelas gráficas. O processo de tradução / adaptação / produção destas graphic novels tende a ser mais complexo que o mesmo processo para uma obra literária composta apenas por letras, dada a interligação própria dos quadrinhos entre os desenhos e o material linguístico e, por conseguinte, as demandas de adaptação gráfica que se tornam relevantes para publicação em mercado estrangeiro. Há estipulações em contrato que determinam, por exemplo, que a versão estrangeira deve ater-se ao formato gráfico da versão no idioma original, que a letreirização deve seguir determinada fonte tipográfica ou, ainda, que a letreirização deve ficar a cargo do autor original (geralmente para ser realizada de forma manual).

Neste contexto, catálogos como o da editora canadense Drawn \& Quarterly (Fig. 8), distribuídos a editores potenciais fora da América do Norte, destacam com asteriscos e letra maior se a obra possui "FONT AVAILABLE" (fonte disponível) ou se "ARTIST WILL RELETTER" (artista disponível para reletreiramento). A disponibilidade de uma fonte digital ou a disposição do autor em refazer o letreiramento em outro idioma - mesmo que estes dois quesitos possam implicar em valor extra na venda dos direitos - aparece, portanto, como fator importante no processo de decisão de um editor estrangeiro em adquirir os direitos de uma obra em quadrinhos. Ao mesmo tempo, ressalta a relevância do letreiramento na expressividade pretendida pelos autores e editores de quadrinhos.

\section{1. Observações teóricas sobre a tradução de quadrinhos}

A tradução das histórias em quadrinhos possui especificidades que até o momento foram pouco abordadas nos Estudos da Tradução. Isto se dá em parte porque os quadrinhos ainda possuem uma trajetória ou status reduzido

TradTerm, São Paulo, v. 27, Setembro/2016, pp. 15-37

www.usp.br/tradterm

http://www.revistas.usp.br/tradterm/index 
ASSIS, É. G. DE - Especificidades da tradução de histórias em quadrinhos: abordagem inicial

como objeto de pesquisa, não somente no campo dos Estudos da Tradução, mas também em outras áreas acadêmicas. Por muitos anos considerados produção descartável e/ou voltada exclusivamente para o público infantojuvenil, nas últimas décadas testemunha-se uma mudança de status dos quadrinhos que os aproximam do status da literatura.

Entre os fatores que contribuem para este status renovado, há a maior penetração das HQs em livrarias, a maior discussão crítica de obras em quadrinhos e a defesa teórico-acadêmica dos quadrinhos como linguagem autônoma e, por conseguinte, objeto de pesquisa relevante (ver, neste sentido, Heer e Worcester 2008; Groensteen 2009; Duncan e SMith 2009; Vergueiro, RAmOS e Chinen 2013). Obras em quadrinhos também desbancaram obras de literatura em prêmios literários da língua inglesa nas últimas décadas: Maus, de Art Spiegelman, ganhou um prêmio Pulitzer em 1992, Jimmy Corrigan, de Chris Ware, um Guardian First Book Award em 2001; Dotter of her father's eye, de Mary e Bryan Talbot, o Costa Book Awards em 2013.

Esta soma de fatores pode reunir-se no termo mercadológico graphic novel, ou novela gráfica (GARCíA 2012), uma espécie de categorização específica para os quadrinhos que são vendidos em livraria, que visam o público adulto e que possuem pretensões artísticas mais elevadas que o estereótipo das HQs.

Este reposicionamento em curso das HQs no sistema de produção cultural e científico tem como uma de suas consequências o repensar da tradução das histórias em quadrinhos. Se anteriormente o status diminuído da mídia implicava em atenção, discussão e crítica diminuídas quanto às suas traduções, a atenção, a discussão e a crítica atualmente começam a atingir níveis comparáveis aos que se veem na literatura. Por outro lado, a prática da tradução de quadrinhos difere em alguns aspectos da tradução de literatura, vistas as diferenças das duas linguagens. 
ASSIS, É. G. DE - Especificidades da tradução de histórias em quadrinhos: abordagem inicial

Zanettin (2008b), organizador do principal livro científico sobre tradução de quadrinhos, afirma que o tema ainda tem "posição marginal nos Estudos da Tradução"2 e que os trabalhos existentes comumente dão ênfase a aspectos ideológicos, à sociologia da tradução e ao viés do leitor infantil. Segundo o mesmo autor (2008a: 39), a maioria dos trabalhos sobre tradução de quadrinhos enfoca separadamente o material linguístico e os desenhos, dando mais atenção ao primeiro. Ignora-se, em muitos casos, que a tradução de quadrinhos exige o entendimento de "texto" no sentido amplo: a soma do material linguístico e dos desenhos. E este texto quadrinístico composto demanda abordagens do tradutor que são diferentes das utilizadas para a tradução em outras mídias.

Esta abordagem presume que as imagens dos quadrinhos traduzidos não passam por modificação, assim restringindo o escopo da investigação à análise linguística. Quadrinhos, contudo, são primariamente textos visuais, cujo significado deriva da interação entre imagens e linguagem escrita. ${ }^{3}$ (ZANETTIN 2008a: 39)

Vigna (2012) reforça esta consideração a respeito da interação imagem $x$ linguagem escrita:

Qualquer compartilhamento de espaço fará com que o texto, além de servir como texto, tenha, também, uma função-imagem. Quero dizer: o texto manterá seu conteúdo literal, de texto, com tudo o que já vimos sobre o que isto significa. Ele será recebido mais lentamente, terá uma aposição de valor, manipulará o tempo de recepção etc. Mas, ao estar acompanhado por uma imagem que com ele compartilha o mesmo espaço, este texto terá também uma forma a ser considerada. Além do seu conteúdo literal, há uma informação visual a ser levada em conta. 0 texto passa a agir como

\footnotetext{
2 Tradução minha. No original: "Comics have mostly been relegated to a marginal position in translation studies."

3 Tradução minha. No original: "This approach assumes that pictures in translated comics are not modified, and thus often restricts the scope of investigation to linguistic analysis. However, comics are primarily visual texts, and meaning derives from the interaction between images and written language, both within and across panel pages."
}

TradTerm, São Paulo, v. 27, Setembro/2016, pp. 15-37

www.usp.br/tradterm

http://www.revistas.usp.br/tradterm/index 
ASSIS, É. G. DE - Especificidades da tradução de histórias em quadrinhos: abordagem inicial

massa tensionante no todo daquela figura presente no espaço. (VIGNA 2012: 192)

Mayoral, Kelly e Gallardo (1988) incluem os quadrinhos entre seus exemplos de "tradução subordinada": “quando a tradução requisitada não é apenas do texto escrito, mas de textos associados a outros meios de comunicação (imagem, música, fontes orais etc.), a função do tradutor é dificultada e ao mesmo tempo subordinada a este outro meio"4 (MAYORAL, Kelly e Gallardo 1998: 356). Os autores apontam que a tradução do material linguístico dos quadrinhos está subordinada à sincronia de conteúdo (linguístico e desenhos) e à sincronia de espaço ("que o sinal ocupe nem mais nem menos espaço do que aquele ao qual corresponde" ${ }^{5}$ [MAYORAL, KELlY e GALLARDO 1998: 356]). Em comparação a outras modalidades de tradução, como tradução musical, legendagem e dublagem, o nível de subordinação é considerado pequeno e comparável às subordinações que acontecem na tradução de publicidade (MAYORAL, KelLy e GALLARDo 1998: 364).

Outro expoente da pesquisa sobre tradução de quadrinhos é Kaindl (2004, 2010). O autor desenvolveu um modelo para análise da tradução de HQs baseado em classificar seus aspectos traduzíveis - grupo linguístico, grupo tipográfico e grupo pictórico (KAINDL 1999, apud TOMÁŠEK 2009, pp. 39) - e elencar estratégias de tradução:

Estas estratégias consistem em repetitio (sinais linguísticos e tipográficos - geralmente também onomatopeias - são absorvidas em sua forma original do discurso fonte), deletio (remoção de texto ou imagens), adiectio (acrescentar um material linguístico ou pictórico ao discurso de chegada), transmutatio (alteração do discurso de chegada na ordem do discurso fonte) e substitutio

\footnotetext{
${ }^{4}$ Tradução minha. No original: "when translation is required not only of written texts alone, but of texts in association with other communication media (image, music, oral sources, etc.), the translator's task is complicated and at the same time constrained by the latter."

${ }^{5}$ Tradução minha. No original: "the signal occupy neither more nor less space than that which corresponds to them".
}

TradTerm, São Paulo, v. 27, Setembro/2016, pp. 15-37 www.usp.br/tradterm http://www.revistas.usp.br/tradterm/index 
AsSIS, É. G. DE - Especificidades da tradução de histórias em quadrinhos: abordagem inicial

(substituição de sinal linguístico, tipográfico ou pictórico por outro). (TOMÁŠEK 2009: 40) ${ }^{6}$

É também Kaindl (2010: 37) que vê na virada cultural dos Estudos da Tradução a maior abertura para as pesquisas sobre quadrinhos. "Sendo a base disto uma noção mais ampla do 'texto', o qual envolve não apenas elementos linguísticos, mas também pictóricos e tipográficos e que considera a tradução de quadrinhos em seus contexto social e cultural."

O mesmo autor levanta como problemas específicos da tradução de quadrinhos a questão mercadológica dos títulos, as diferenças na representação de tempo e espaço que exigem adietio ${ }^{7}$, onomatopeias, trocadilhos visuais e design tipográfico, entre outros - especificando que aspectos como este último, do design tipográfico, "raramente foram considerados ao se examinar traduções” (Kaindl 2010: 39).

\section{Especificidades da tradução de histórias em quadrinhos}

Considerando o breve exposto teórico referente à tradução de quadrinhos, combinado à renovação do status de certa parcela da produção

\footnotetext{
${ }^{6}$ Tradução minha. No original: "Those strategies are repetitio (linguistic and typographic signs - and usually onomatopoeia as well - are taken over in their original form from the source discourse), deletio (removal of text or pictures), adiectio (adding a linguistic or pictorial material to the target discourse), transmutatio (change of the target discourse in order of the source discourse) and substitutio (replacement of one linguistic, typographic or pictorial sign with another)."

7 "Whereas only short time gaps between panels are normally common in the Germanspeaking area, for instance, when not linguistically specifying otherwise, in American comics, several hours can pass by between two panels without linguistically stating this. As a result, narrating texts sometimes have to be inserted when translating from American English into German." (KAINDL 2010: 38)
}

TradTerm, São Paulo, v. 27, Setembro/2016, pp. 15-37

www.usp.br/tradterm

http://www.revistas.usp.br/tradterm/index 
ASSIS, É. G. DE - Especificidades da tradução de histórias em quadrinhos: abordagem inicial

mundial de HQs, pode-se propor alguns outros elementos específicos à tradução de quadrinhos para firmar sua diferença frente à tradução praticada em outras mídias.

Inicialmente, propõe-se cinco especificidades, a serem analisadas à frente:

1. Ingerência do tradutor reduzida às unidades de material linguístico

2. Indissolubilidade da mancha gráfica

3. Indissolubilidade das quebras verbais

4. Documento de tradução = roteiro para letreirista

5. O letreirista como cotradutor

\section{Ingerência do tradutor reduzida às unidades de material linguístico}

Se, como já apontado pelos demais autores, a linguagem dos quadrinhos baseia-se na concatenação entre o material linguístico e os desenhos, pode-se dizer que o “texto" dos quadrinhos é a articulação entre estes dois aspectos. O tradutor de quadrinhos, porém, só terá ingerência sobre o material linguístico.

Esta parcela linguística é a que está disposta em balões (falas e pensamentos), recordatórios (comumente localizadores de tempo e espaço como “Nova York, hoje" ou “enquanto isso"), inscrições (placas, jornais, letreiros etc. inseridos no âmbito do desenho) e onomatopeias. Na produção comercial digitalizada de revistas de quadrinhos, estes elementos costumam ser produzidos separadamente da composição pictórica da página - ou seja, em uma camada diferenciada do arquivo digital - de forma a facilitar a editoração do produto original e, por conseguinte, a tradução e publicação em mercados estrangeiros (Fig. 9 e 10). 
ASSIS, É. G. DE - Especificidades da tradução de histórias em quadrinhos: abordagem inicial

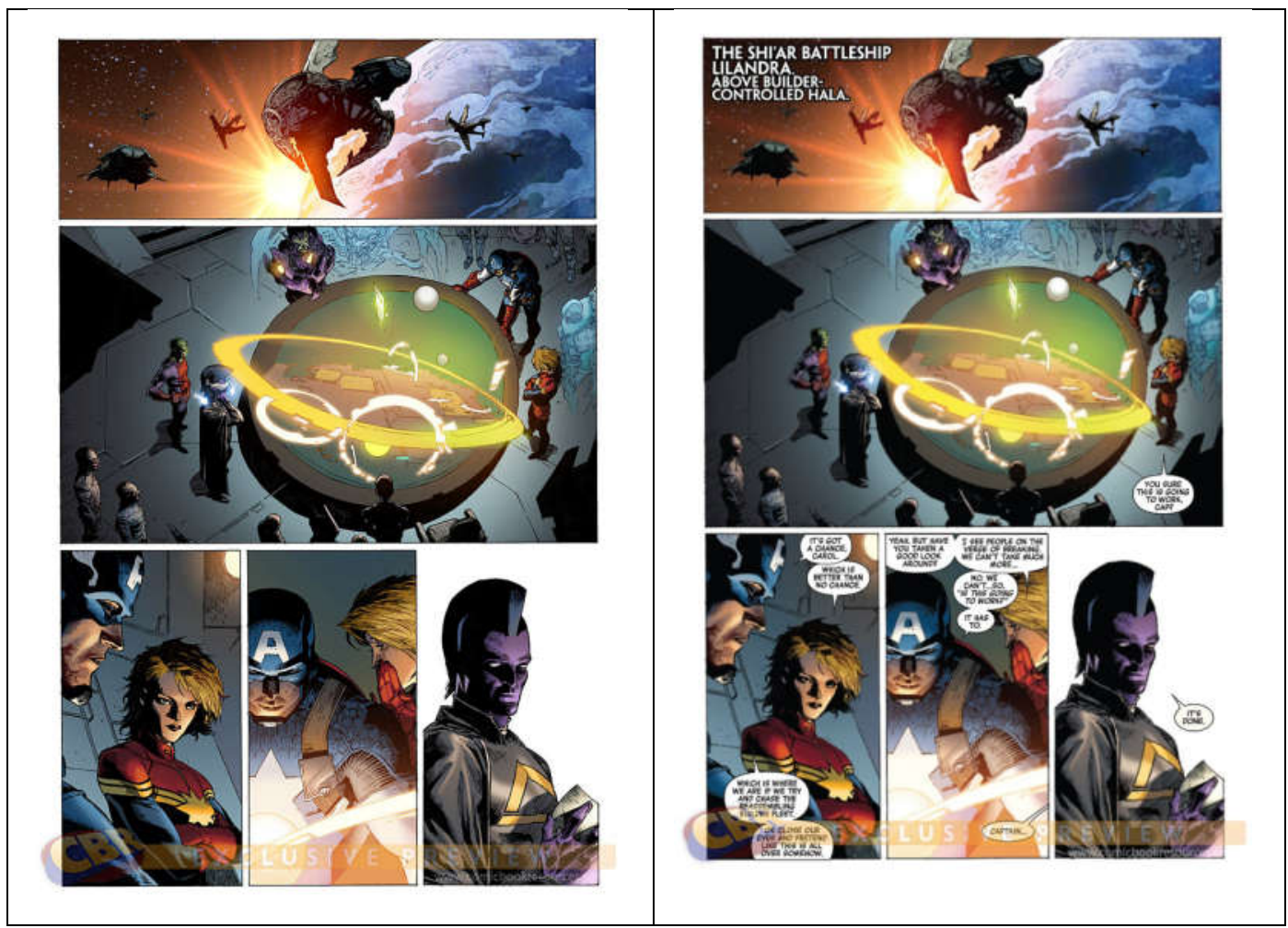

Fig. 9 e 10: Prévia (esquerda) e versão final de página da HQ Infinity \#4 (2013), com aplicação posterior de material linguístico.

Fonte: http: / /www.comicbookresources.com/?page=preview\&id=18322 e http: / / www.comicbookresources.com/?page=preview\&id=18406

Já nas novelas gráficas, o quadrinho de status literário, é mais comum encontrar estes elementos de material linguístico trabalhados de forma rebuscada, com inovações de linguajar e explorações tipográficas. Ocorrem momentos em que o quadrinista insere estes elementos linguísticos concatenados com o pictórico, inclusive criando relação mais intrínseca entre as formas desenhadas e as letras - ou, em outras palavras, as letras assumem um valor tanto de desenho quanto de material linguístico. Consequentemente, a tradução destes quadrinhos é dificultada por exigir maior habilidade e tempo de produção da parte de tradutor e letreirista (Fig. 11). 
ASSIS, É. G. DE - Especificidades da tradução de histórias em quadrinhos: abordagem inicial

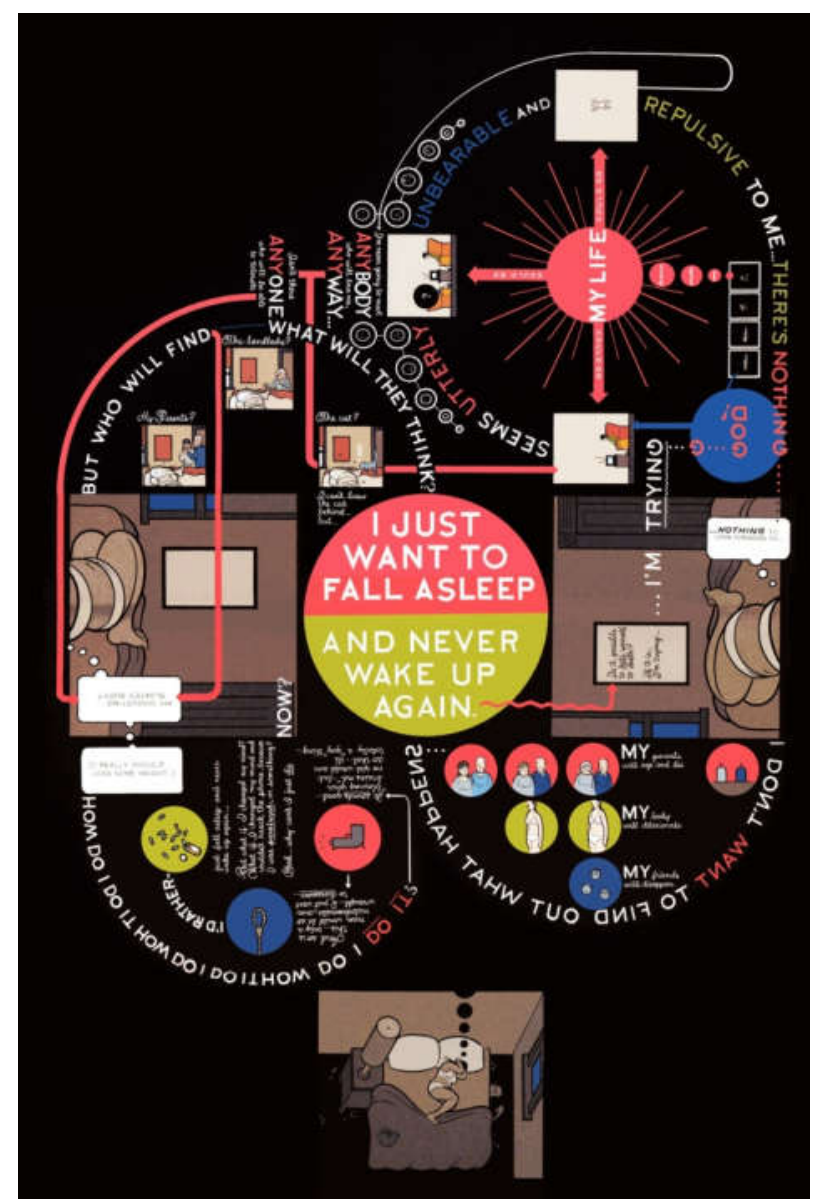

Fig. 11: Exemplo de integração elevada entre desenho e material linguístico em $\mathrm{HQ}$ (WARE 2012: s.p.).

Os desenhos, por sua vez, raramente sofrem alterações na tradução contemporânea de quadrinhos. 0 exemplo com Peanuts que abre este artigo é um destes exemplos raros; os outros incluem casos de mudanças de formato ou censura ${ }^{8}$. Atualmente, porém, a valorização da narrativa em quadrinhos ao nível artístico exige - às vezes ao nível contratual - que os desenhos sejam irretocados. Mesmo se esta exigência não existir, o ritmo de produção editorial solicita que estas alterações não sejam empreendidas - de forma que

\footnotetext{
${ }^{8}$ Em outro exemplo, uma história do super-herói Demolidor, de 1985, uma personagem está prestes a injetar-se uma dose de heroína via seringa. Na primeira vez em que a história foi publicada no Brasil, em 1987, a seringa foi redesenhada: foi substituída por uma navalha para evitar a referência a drogas. (Maron, 1999, online).
} 
ASSIS, É. G. DE - Especificidades da tradução de histórias em quadrinhos: abordagem inicial

o tradutor trabalha comumente com a presunção de que só deverá alterar o material linguístico.

\section{Indissolubilidade da mancha gráfica}

A valorização da página de quadrinhos ao nível artístico também leva a seu entendimento como unidade composicional a ser respeitada no processo de tradução. Fazem parte desta composição o posicionamento de elementos verbais como balões e recordatórios e, igualmente, a mancha gráfica interna a estes elementos. Ou seja: a área de um balão ou recordatório ocupada pelo material linguístico deve ser similar no texto de partida e no texto de chegada, de forma a preservar o equilíbrio estético da página. É a efetivação da sincronia espacial apontada pela teoria da tradução subordinada (MAYORAL, KelLy e GaLlardo 1988).
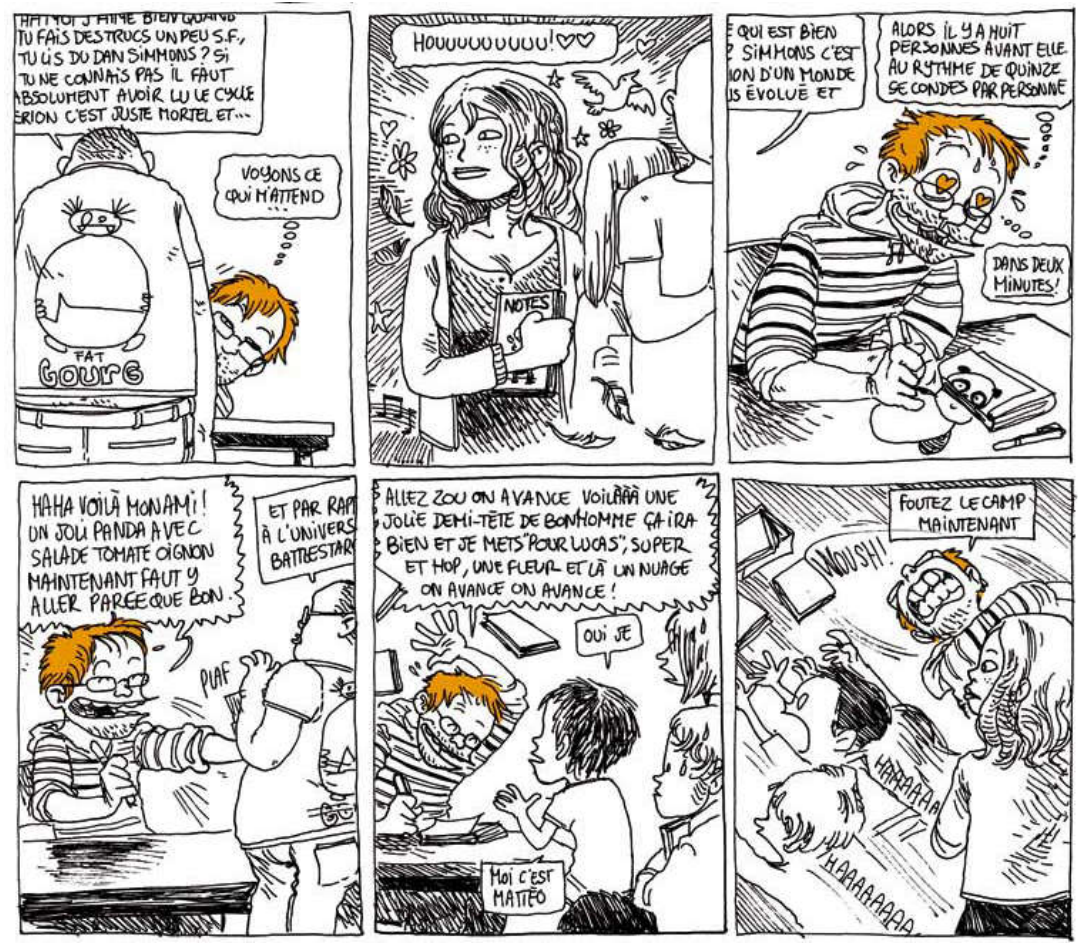

Fig. 12: http: / /www.bouletcorp.com/blog/2009/07/11/rencontres-dedicaces-avotre-service/ (2009) 
ASSIS, É. G. DE - Especificidades da tradução de histórias em quadrinhos: abordagem inicial
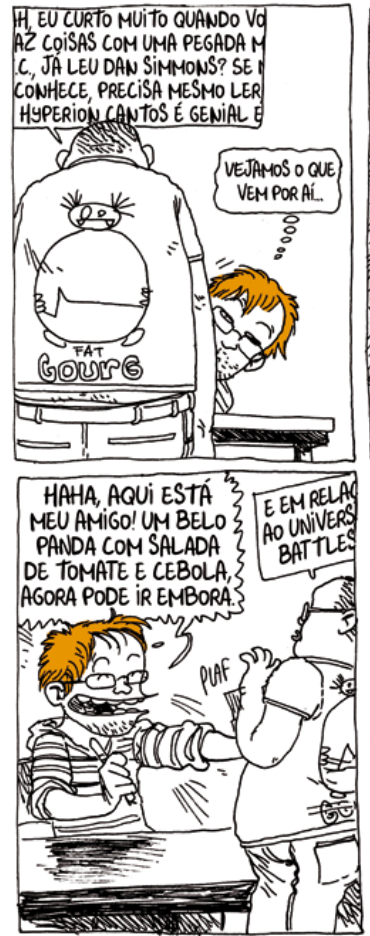
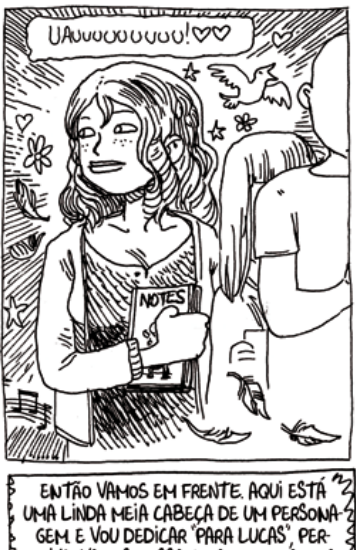
3 UMA LINDA MEIA CABECA DE UM PERSONA-
GEM E VOU DEDICAR 'PARA LUCAS", PER FEITO. VAMOS NESSA, UMA FL ORE AGORA 7 UMA NUVEM O PRÓXIMO, O PRÓXIMO!

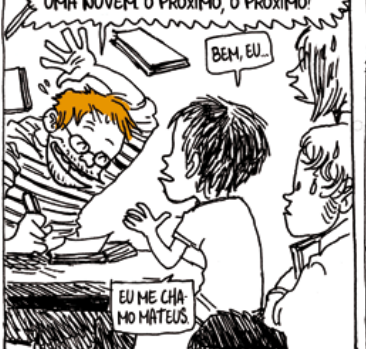

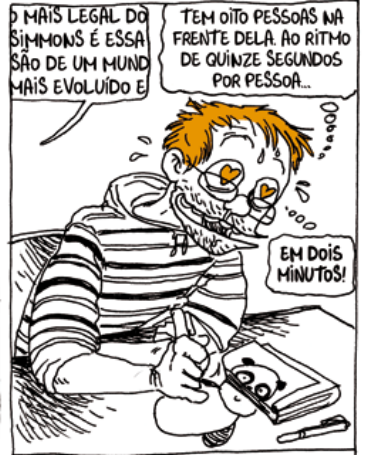

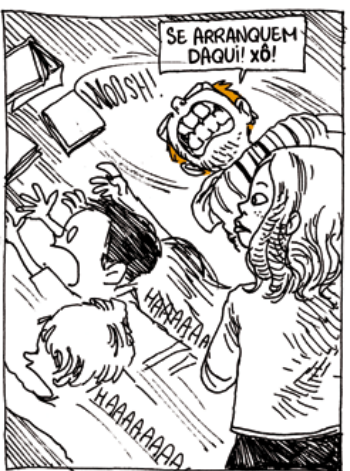

Fig. 13: http://outrosquadrinhos.com.br/hq/boulet-corp/encontros-pg-1/ (2013)

O exemplo de tradução nas figuras 12 e 13 demonstra (1) a atenção do tradutor em prover texto suficiente (nem mais, nem menos) para preencher a área dos balões de forma similar ao original e (2) a atenção do letreirista quanto a variações de tamanho de letra, quantidade de linhas por balão e outras variações determinadas no letreiramento original. Da mesma forma, vê-se que foram mantidos os contornos dos balões e seus posicionamentos. A composição de massas da página desenhada é mantida.

\section{Indissolubilidade das quebras verbais}

Enquanto o texto de prosa é mais aberto, na tradução, à reorganização de construções verbais como frases e parágrafos, a tradução de quadrinhos deve respeitar as quebras do material linguístico determinadas pelas ocorrências de balões e recordatórios. A construção de uma fala, por exemplo, obrigatoriamente segue a sua divisão em sucessivos balões, da forma como esta fala é repartida no texto original. 
ASSIS, É. G. DE - Especificidades da tradução de histórias em quadrinhos: abordagem inicial

As histórias em quadrinhos atuais possuem uma tendência à fragmentação das falas em balões de poucas palavras. O longo discurso de um personagem, por exemplo, é disposto em vários quadros para estabelecer o ritmo da história e determinar a velocidade de leitura e carga dramática de uma sequência.

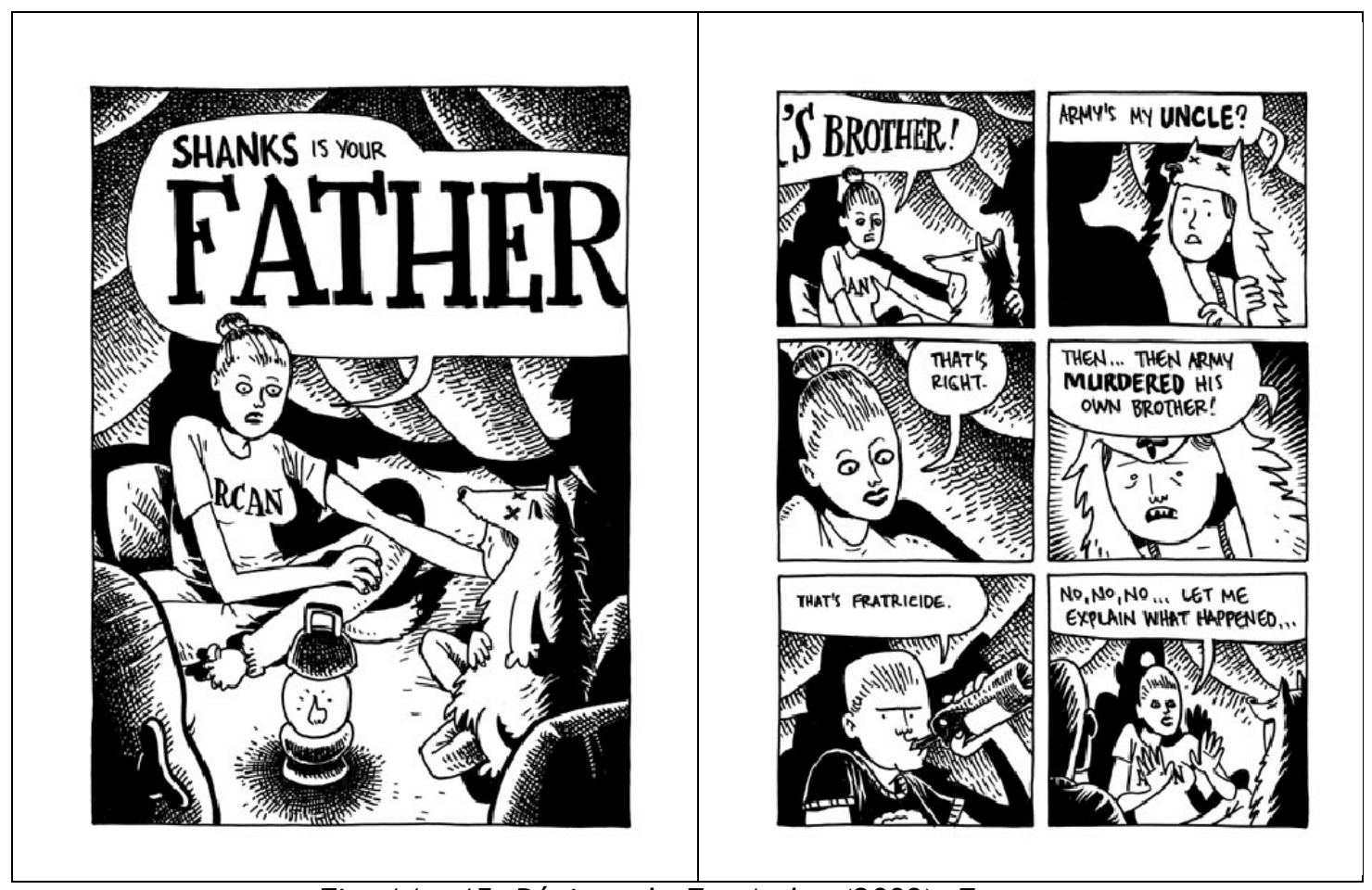

Fig. 14 e 15: Páginas de Far Arden (2009). Fonte:

http: //www.kevincannon.org/288hour/chapter08.html

O exemplo das figuras 14 e 15 registra uma situação em que o autor faz uso da quebra de páginas para estabelecer um momento de forte carga dramática em sua trama. Além disso, utiliza a regra dos possessivos da língua inglesa para armar uma surpresa na revelação ao leitor sobre o parentesco de um personagem.

Apesar de fugir do usual, o exemplo mostra uma possível dificuldade a que o tradutor de quadrinhos está sujeito dadas as possibilidades da linguagem das HQs. 
ASSIS, É. G. DE - Especificidades da tradução de histórias em quadrinhos: abordagem inicial

4. Documento de tradução = roteiro para letreirista

Por conta de exigir habilidades distintas e também devido ao ritmo de produção editorial, o processo de tradução de histórias em quadrinhos costuma ser dividido entre um profissional tradutor e um profissional letreirista. O primeiro faz a adaptação do material linguístico do texto exercício interpretativo e redacional similar à tradução de prosa e outras variantes de escrita. Já o letreirista é o responsável por aplicar as ocorrências verbais traduzidas à página - exercício interpretativo e técnico que, no contexto de mercado atual, exige domínio de softwares de edição de imagens.

Desta forma, o documento de tradução comumente entregue pelo tradutor à editora de quadrinhos consiste em um roteiro de aplicação das ocorrências verbais sobre a página, que servirá de orientação ao serviço do letreirista. 
ASSIS, É. G. DE - Especificidades da tradução de histórias em quadrinhos: abordagem inicial
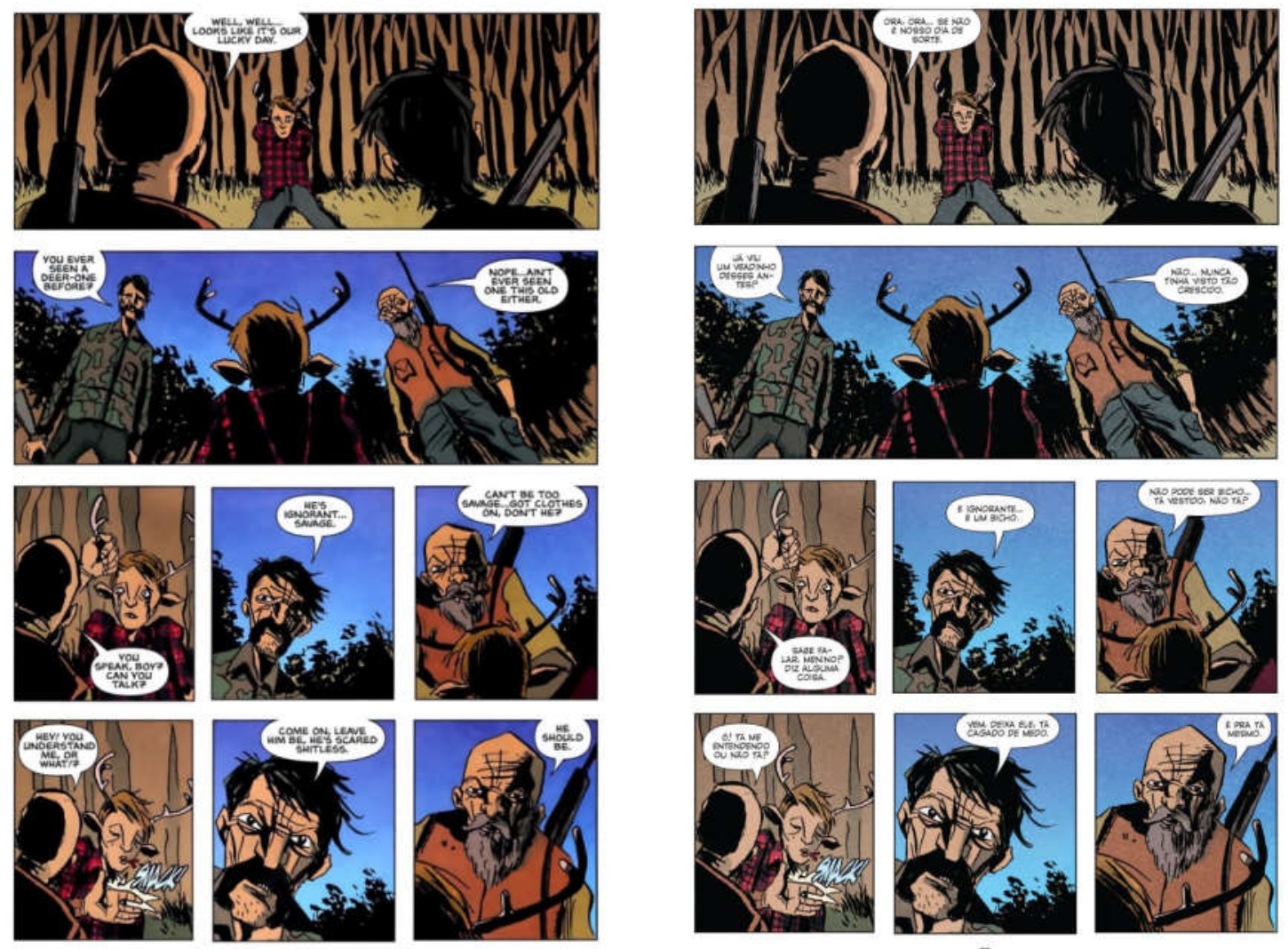

Fig. 16 e 17: Páginas de Lemire (2010) e Lemire (2012). Obs.: as variações de cor não correspondem ao material impresso - o motivo é a conversão dos arquivos digitais.

No caso da editora brasileira Panini, que publica grande volume de quadrinhos traduzidos, a tradução é dividida entre as etapas do tradutor propriamente dito e do letreirista (além de revisor e editor). A editora estabelece um padrão de entrega da tradução que consiste em numerar as ocorrências de material linguístico de uma página segundo sua ordem de leitura9. A tradução da página na figura 16 para a página na figura 17 foi roteirizada pelo tradutor da seguinte forma:

\footnotetext{
${ }^{9}$ Caso a ordem de leitura não seja clara, o tradutor pode usar notas de orientação junto ao documento.
} 
ASSIS, É. G. DE - Especificidades da tradução de histórias em quadrinhos: abordagem inicial

\section{PÁGINA 20}

1. ORA, ORA... NOSSO DIA DE SORTE.

2. JÁ VIU UM VIADINHO DESSES?

3. NÃO... NUNCA TINHA VISTO TÃO CRESCIDO.

4. SABE FALAR, MENINO? DIZ ALGUMA COISA.

5. É IGNORANTE... É UM BICHO.

6. NÃO PODE SER BICHO... TÁ VESTIDO, NÃO TÁ?

7. Ô! TÁ ME ENTENDENDO OU NÃO TÁ?

8. VEM, DEIXA ELE, TÁ CAGADO DE MEDO.

9. É PRA TÁ. ${ }^{10}$

Esta divisão de trabalho implica em que o tradutor não tem visualização final ou aproximada do texto quadrinístico traduzido da forma como chegará ao leitor final - como teria, pelo menos de forma aproximada, na prosa. A adequação da quantidade de caracteres ao balão (especificidade 2) é aproximada, e é possível que editor ou letreirista façam adequações nas suas respectivas etapas de produção, diminuindo ou aumentando o número de palavras (ou optando por sinônimos de menos ou mais caracteres) de forma que se preserve a mancha gráfica interna a um balão ou recordatório.

\section{O letreirista como cotradutor}

Como já está entrevisto nas especificidades acima, o letreirista (também creditado como “letrista”, “letras” ou “composição”) tem parcela de importância elevada no processo de tradução de histórias em quadrinhos. É este profissional que preserva a mancha gráfica, que atenta a questões tipográficas expressivas e como reproduzí-las na tradução, e que efetivamente aplica o material linguístico traduzido à página de $\mathrm{HQ}$, tendo a

\footnotetext{
${ }^{10}$ Arquivo pessoal.
} 
ASSIS, É. G. DE - Especificidades da tradução de histórias em quadrinhos: abordagem inicial

partir daí condições de comparar/interpretar o processo completo de tradução.

Esta possivelmente seria a especificidade de maior relevância na tradução de quadrinhos. O diagramador das traduções de prosa, assim como o legendador e profissionais técnicos que se envolvem em outras modalidades de tradução de língua escrita, não desempenham a mesma função de reproduzir aspectos estéticos (tipografia, composição, indissolubilidade da mancha gráfica) que o letreirista.

O único ponto de similaridade no mercado editorial estaria nos letreiristas ou diagramadores envolvidos no processo de tradução de um livro ilustrado, que pode solicitar as mesmas exigências gráficas e estéticas. A importância elevada do material linguístico como parte da narrativa do quadrinho, porém, confere ao letreirista uma responsabilidade diferenciada destas outras modalidades de tradução: a reprodução, no texto quadrinístico traduzido, da expressividade do texto quadrinístico fonte está condicionada igualmente à adequação do material linguístico e ao tratamento pictórico deste material linguístico na página de HQ.

Dito que o texto quadrinístico consiste na união entre o material linguístico e os desenhos e que o processo de tradução de quadrinhos inevitavelmente lida com estes dois aspectos de forma simultânea - dado que o material linguístico também é desenhado e sua expressividade por vezes está condicionada à forma como as letras são desenhadas -, e dito também que o tradutor só possui ingerência sobre o material linguístico, é plausível afirmar que o letreirista desempenha papel de tamanha relevância na tradução de quadrinhos que deve ser considerado um cotradutor. 
ASSIS, É. G. DE - Especificidades da tradução de histórias em quadrinhos: abordagem inicial

\section{Considerações finais}

0 presente artigo representa um primeiro olhar sobre especificidades da tradução de histórias em quadrinhos que, segundo o levantamento da reduzida bibliografia específica do assunto (TOMÁšEK 2009; ZANETTIN 2008, 2008b, 2010; KAINDL 2004, 2010), ainda não teriam sido abordadas por pesquisadores da área. São especificidades que dizem respeito à forma de expressão própria dos quadrinhos, e entender que os quadrinhos constituem uma forma de expressão própria ou constituem mídia particular e digna de apuro analítico é algo relativamente recente nos estudos acadêmicos.

Com a mudança em curso do status das histórias em quadrinhos como objeto de estudo e também como produto cultural de relevância, entende-se que também a pesquisa sobre a tradução de quadrinhos deve ganhar impulso. Este e futuros trabalhos apresentam-se como contribuições para este pequeno nicho de pesquisa em formação.

\section{Referências Bibliográficas}

GarcíA, S. A novela gráfica. Trad. Magda Lopes. São Paulo: Martins Fontes, 2012.

Groensteen, T. The system of comics. Trad. Bart Beaty e Nick Nguyen. University Press of Mississippi, 2009.

HEER, J.; WORCESTER, K. A comics studies reader. University Press of Mississippi, 2008.

KAINDL, K. Comics in translation. In: GAMBIER, Y.; VAN DOoRsLAER, L. Handbook of translation studies vol. 1. John Benjamins Publishing Company, 2010: 36-40.

KAINDL, K. Multimodality in the translation of humour in comics. In: VENTOLA, E.; Charles, C.; Kaltenbacher, M. Perspectives on multimodality. John Benjamins Publishing Company, 2004: 173-192.

LEMIRE, J. Sweet Tooth vol. 1: Out of the Woods. New York: DC Comics/Vertigo, 2010. 
ASSIS, É. G. DE - Especificidades da tradução de histórias em quadrinhos: abordagem inicial

LEMIRE, J. Sweet Tooth - Depois do Apocalipse vol. 1: Saindo da Mata. Trad. Érico Assis. São Paulo: Panini, 2012.

Maron, A. Demolidor perde tudo outra vez. Folha de S. Paulo, 4 ago. 1999. Disponível em: www.folha.uol.com.br/fsp/ilustrad/fq04089913.htm. Acesso em: 3 dez. 2013.

MAYORAL, R.; Kelly, D.; Gallardo, N. Concept of Constrained Translation. Nonlinguistic perspectives of translation. Meta: journal des traducteurs / Meta: Translator's Journal, vol. 33, n. 3, 1988, pp. 356-367. Disponível em: www.erudit.org/revue/meta/1988/v33/n3/003608ar.html?vue=resume.

Acesso em: 3 dez. 2013.

O’Malley, B. L. Scott Pilgrim vs. the world. Portland: Oni Press, 2005.

O’Malley, B. L. Scott Pilgrim contra o mundo vol. 1. Trad. Érico Assis. São Paulo: Companhia das Letras, 2010.

PAZ, L. Review: Asilo Arkham - uma séria casa em um sério mundo - edição definitiva. Universo $H Q, 22$ fev. 2013. Disponível em: www.universohq.com/quadrinhos/2013/review_AsiloArkham.cfm. Acesso em: 3 dez. 2013.

TOMÁŠEK, O. Translating Comics. Tese de Mestrado, Masaryk University, 2009. Disponível em: http://is.muni.cz/th/146660/ff_m/Thesis_-_final.pdf. Acesso em: 3 dez. 2013.

TRANSATLANTIC AgENCY. Drawn and Quarterly Rights Hotlist: graphic novels fall/winter 2013-2014. Disponível em: www.transatlanticagency.com/wpcontent/uploads/2013/10/dq_hotlist_fallwinter20132014_sm.pdf. Acesso em: 3 dez. 2013.

Vergueiro, W.; Ramos, P.; Chinen, N. Intersecções Acadêmicas: panorama das 1 as Jornadas Internacionais de Histórias em Quadrinhos. São Paulo: Criativo, 2013.

VIGNA, E. Os sons das palavras: possibilidades e limites da novela gráfica. In: DALCASTAGnè, R. Histórias em quadrinhos: diante da experiência dos outros. Vinhedo: Horizonte, 2012.

Zanettin, F. Comics. Verbete in: Baker, M.; SAldanha, G. Routledge Encyclopedia of Translation Studies. Londres: Routledge, 2008 (a): 37-40.

Zanettin, F. Comics in translation. St. Jerome Publishing, 2008 (b).

Zanettin, F. Humour in Translated Cartoons and Comics. In: CHIARO, D. Translation, Humour and the Media. Bloomsbury, 2010: 34-52.

WARE, C. Building Stories. New York: Pantheon, 2012. 